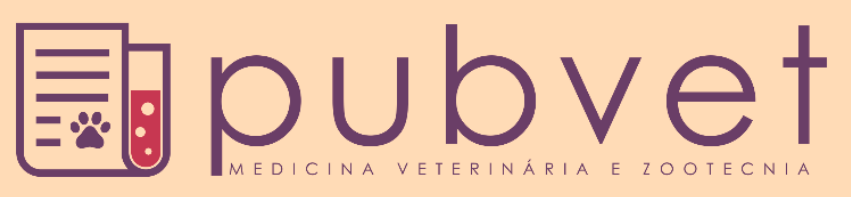

https://doi.org/10.31533/pubvet.v14n9a659.1-12

\title{
Gestão tributária e competitividade na cadeia produtiva de ração para cães e gatos no Estado de São Paulo
}

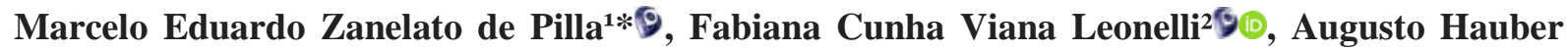 \\ Gameiro ${ }^{390}$
}

${ }^{1}$ Mestre pelo Programa de pós-graduação e Gestão e Inovação na Indústria Animal, Faculdade de Zootecnia e Engenharia de Alimentos, Universidade de São Paulo (FZEA-USP)

${ }^{2}$ Docente na Faculdade de Zootecnica e Engenharia de Alimentos da Universidade de São Paulo (FZEA-USP)

${ }^{3}$ Docente da Faculdade de Medicina Veterinária e Zootecnia da Universidade de São Paulo (FMVZ-USP)

*Autor para correspondências, Email marcelo.zanelato@usp.br

\begin{abstract}
Resumo. Este trabalho visou analisar e compreender a tributação da ração para cães e gatos e calcular e comparar sua carga tributária incidente na cadeia produtiva. As estratégias de gestão tributária são relevantes e influenciam na competitidade empresarial. O Sistema Tributário Nacional (STN) possui concentração mais elevada na tributação das bases de bens e serviços se comparado a média dos países da Organização para a Cooperação e Desenvolvimento Econômico (OCDE). Os governos procuram manterem suas arrecadações através de políticas fiscais, sendo constantemente apontadas as necessidades de reformulações em diversos setores dada a siginificativa carga tributária existente no país. Esta pesquisa foi desenvolvida com base em levantamento bibliográfico, documental e na legislação tributária, sendo uma abordagem qualitativa, descritiva e exploratória. Elaborouse uma simulação da carga tributária ao longo da cadeia produtiva da ração pet com base na legislação pertinente, obteve-se um percentual de carga tributária na indústria de $52,63 \%$, sobre o distribuidor de 6,61\% e sobre o pet shop de 7,30\%. Em 2016 a carga tributária média nacional foi de $32,38 \%$ do Produto Interno Bruto (PIB) e elevou nos dois anos seguintes, enquanto comparando com a simulação elaborada obteve-se que o consumidor pagou ao comprar a ração pet, $41,86 \%$ de impostos, acumulados ao longo da cadeia produtiva. Notou-se que a tributação da ração pet está 9,48 p.p. maior que a média nacional daquele ano. A tributação da ração pet vêm sendo apontada constantemente por empresários e entidades do setor como excessiva e um dos principais obstáculos de desenvolvimento. Outrossim, percebe-se que o governo ainda não reconhece os inumeros benefícios trazidos por estes animais de estimação para sociedade, visto os aumentos constantes na carga tributária destes produtos.
\end{abstract}

Palavras chave: agronegócio, mercado pet, planejamento tributário, contabilidade tributária

\section{Tax management and competitiveness in the production chain of dog and cat food in the State of São Paulo}

Abstract. This work aimed to analyze and understand the taxation of dog and cat food and
to calculate and compare its tax burden on the production chain. Tax management strategies
are relevant and influence business competitiveness. The National Tax System (STN) has
a higher concentration on the taxation of the bases of goods and services if compared to the
average of the countries of the Organization for Economic Cooperation and Development
(OECD). Governments seek to maintain their collections through tax policies, with the
need for reforms in various sectors being constantly pointed out given the significant tax
burden existing in the country. This research was developed based on bibliographic, 
documental and tax legislation surveys and is a qualitative, descriptive and exploratory approach. A simulation of the tax burden along the production chain of pet food was prepared based on the pertinent legislation, obtaining a tax burden percentage in the industry of 52.63\%, on the distributor of $6.61 \%$ and on the pet shop of $7.30 \%$. In 2016, the average national tax burden was 32.38\% of Gross Domestic Product (GDP) and increased in the following two years, while comparing with the simulation prepared, it was obtained that the consumer paid when buying pet food, $41.86 \%$ of taxes, accumulated along the production chain. It was noted that pet food taxation is 9.48 p.p. higher than the national average for that year. The taxation of pet food has been pointed out constantly by entrepreneurs and entities in the sector as excessive and one of the main obstacles to development. Moreover, it is noticeable that the government still does not recognize the innumerable benefits brought by these pets to society, given the constant increases in the tax burden of these products.

Keywords: agribusiness, pet market, tax planning, tax accounting

\section{Gestión de impuestos y competitividad en la cadena de producción de alimentos para perros y gatos en el Estado de São Paulo}

Resumen. Este trabajo tenía como objetivo analizar y comprender la fiscalidad de los alimentos para perros y gatos y calcular y comparar su carga fiscal en la cadena de producción. Las estrategias de gestión fiscal son pertinentes e influyen en la competitividad de las empresas. El Sistema Tributario Nacional (STN) tiene una mayor concentración en la tributación de las bases de bienes y servicios si se compara con el promedio de los países de la Organización de Cooperación y Desarrollo Económicos (OCDE). Los gobiernos procuran mantener sus recaudaciones mediante políticas fiscales, señalando constantemente la necesidad de reformas en diversos sectores, dada la importante carga fiscal existente en el país. Esta investigación se desarrolló sobre la base de estudios bibliográficos, documentales y de legislación fiscal y es un enfoque cualitativo, descriptivo y exploratorio. Se preparó una simulación de la carga fiscal a lo largo de la cadena de producción de alimentos para animales domésticos basada en la legislación pertinente, obteniendo un porcentaje de carga fiscal en la industria del 52,63\%, en el distribuidor del $6,61 \%$ y en la tienda de animales del 7,30\%. En 2016, la carga fiscal media nacional era del 32,38\% del Producto Interno Bruto (PIB) y aumentó en los dos años siguientes, mientras que comparando con la simulación preparada, se obtuvo que el consumidor pagaba al comprar alimentos para animales domésticos, el 41,86\% de los impuestos, acumulados a lo largo de la cadena de producción. Se observó que los impuestos sobre los alimentos para animales domésticos son 9,48 p.p. más altos que la media nacional de ese año. Los empresarios y las entidades del sector han señalado constantemente que la imposición de impuestos a los alimentos para animales domésticos es excesiva y uno de los principales obstáculos para el desarrollo. Por otra parte, se observa que el gobierno sigue sin reconocer los innumerables beneficios que aportan estos animales domésticos a la sociedad, habida cuenta de los constantes aumentos de la carga fiscal de estos productos.

Palabras clave: agroindustria, mercado de mascotas, planificación fiscal, contabilidad fiscal

\section{Introdução}

Os animais de companhia possuem um papel social importante, sendo considerados, praticamente, como membros da família. A importância dada aos "pets" - expressão utilizada para animais domésticos - é decorrente dos benefícios obtidos a partir do vínculo afetivo estabelecidos com os mesmos, influenciando a vida e a saúde humana de formas diversas (Heiden \& Santos, 2009). Essa relação tão próxima favoreceu o crescimento e a diversificação do mercado de alimentos para cães e gatos, visto que a relação de afetividade se reflete no consumo e, principalmente, no momento da compra de alimento para estes animais. 
A cadeia produtiva de ração para cães e gatos possui grande demanda de especialização, seja em âmbito técnico, seja em âmbito gerencial. Com o crescimento acelerado deste setor, percebe-se um aumento da competição gerada pela atratividade deste negócio, sendo necessária a implementação de estratégias competitivas para garantir um posicionamento vantajoso no mercado.

No tocante à tributação incidente em rações para pets, este tema vem sendo pauta de discussões entre o governo, entidades de classe e empresários, sendo considerada por estes últimos como excessiva e prejudicial ao desenvolvimento do setor, apesar de apresentar crescimento de $11 \%$ no período de 2012 a 2017, segundo o Euromonitor International (2018).

Em virtude da complexidade que este tema suscita, o mesmo foi objeto de uma investigação de mestrado, onde foram enfatizados apenas os aspectos tributários relevantes incidentes em alimentos completos para cães e gatos, conceituados de acordo com a Portaria 3/2009 do Ministério da Agricultura, Pecuária e Abastecimento em seu Anexo I, Art. $3^{\circ}$ § II, (MAPA, 2009).

Assim, buscou-se, neste trabalho, analisar e compreender a tributação da ração para cães e gatos e calcular e comparar sua carga tributária incidente na cadeia produtiva.

\section{Material e Métodos}

A presente pesquisa está relacionada à área contábil, mais especificamente ao ramo que trata da tributação (impostos) das pessoas jurídicas. Então chamada de Contabilidade Tributária, seu estudo é relevante na atualidade para qualquer economia, notadamente para o Brasil, que possui elevada carga tributária em algumas categorias, além da complexidade do sistema tributário nacional, em face da significativa quantidade de impostos e normas existentes no país. Assim, para responder ao problema proposto, além do levantamento e interpretação da legislação pertinente, utilizou-se da elaboração de uma simulação de aplicação prática, com base em um caso hipotético, para o cálculo da carga tributária da ração para cães e gatos, já que o acesso a informações tributárias é restrito às empresas.

Contudo, esta pesquisa, no que se refere à abordagem do problema, se caracteriza como qualitativa. Quanto aos seus objetivos, se enquadra como pesquisa descritiva e exploratória. Os procedimentos utilizados foram o levantamento bibliográfico e a pesquisa documental sobre a legislação tributária, fazendo uso de análises estruturadas, interpretação da legislação e comparações da carga tributária apurada. Os instrumentos utilizados preponderantemente na pesquisa foram a legislação tributária e a documentação coletada pelo pesquisador na internet em sites que tratam deste assunto, como o da ABINPET, o Euromonitor e os da Secretaria de Fazenda do Estado de São Paulo, da Receita Federal do Brasil e do Instituto Brasileiro de Planejamento e Tributação. Os dados foram analisados de forma descritiva e documental. Ressalta-se o volume de dispositivos legais pesquisados, relativos à interpretação e aplicabilidade específica, que revelam a incidência de cada tributo sobre a ração para cães e gatos.

Além do levantamento bibliográfico, também foi utilizada a pesquisa documental, a fim de analisar e interpretar a legislação pertinente e sua aplicação prática no contexto corporativo das empresas da cadeia produtiva de ração pet. Foram pesquisadas e comparadas demonstrações contábeis de empresas do setor, diversas legislações relacionadas e demais informações publicadas e disponíveis na Secretaria da Receita Federal, Secretaria da Fazenda Nacional, Instituto Brasileiro de Planejamento Tributário, Conselho Administrativo de Recursos Fiscais, Conselho Federal de Contabilidade e Comitê de Pronunciamentos Contábeis, Jurisprudências e Consultas Tributárias Específicas.

Na elaboração da simulação da carga tributária da ração, utilizou-se de planilhas eletrônicas no software Microsoft Excel e os resultados obtidos foram analisados e comparados com a média de tributação de outros produtos no contexto nacional e internacional.

É necessário destacar que as questões tributárias se valem de análises e interpretações da legislação, compreendendo as discussões de mérito do Direito e sua aplicação normativa, corroborando para soluções de questões ainda consideradas controversas no âmbito administrativo e judicial, a fim de se ter a aplicação da legislação mais vantajosa e segura aos contribuintes.

Para esta simulação da carga tributária da ração para cães e gatos foram consideradas apenas as vendas internas no Estado de São Paulo. A respeito da legislação tributária, não serão aqui consideradas 
as questões controversas. Medidas judiciais a título de planejamento tributário serão posteriormente analisadas apenas como alternativas para redução do ônus tributário. Assim, buscou-se aplicar apenas a legislação, com base no entendimento da Receita Federal, para mitigação dos riscos tributários, adotando postura conservadora. Os dados apresentados são hipotéticos, com o único objetivo de servirem de referência para a apuração da carga tributária.

\section{Mudanças sociais e o aumento do afeto por pets}

A humanização dos animais, fenômeno conhecido como antropomorfismo, é um processo onde se imputa estados mentais antropomorfizados aos animais, sendo comum que as pessoas se refiram aos seus animais como se fossem seus familiares, visto que os animais são tratados com afeto próprio àquele destinado aos membros da família no ambiente privado e nos momentos de lazer (Pessanha \& Carvalho, 2014).

As mudanças sociais e na relação dos humanos com seus animais de estimação são tão significativas que propiciam inclusive alterações no ordenamento jurídico relativo à guarda desses animais em caso de separação dos tutores. Assim entendeu a $7^{\text {a }}$ Câmara de Direito Privado do Tribunal de Justiça de São Paulo, ao reconhecer que as Varas de Família são competentes para solucionar questões relativas à guarda e à visita de animais de estimação, conforme acórdão publicado pelo Tribunal de Justiça de São Paulo, registro 2018.0000202789 (TJ-SP, 2018).

\section{Panorama do mercado pet}

Conforme o relatório do Euromonitor International (2018), a América do Norte continua sendo o maior mercado pet, em grande parte graças à humanização desses animais de estimação. Em virtude deste fenômeno, o crescimento da categoria alimento premium também tem sido revelante, pois os consumidores estão optando por alimentos e produtos de maior qualidade e valor agregado. As ofertas de ração premium e voltadas a nichos (por exemplo, rações para raças específicas ou medicamentosas) têm crescido, com aumento do número de produtos e opções de ingredientes, como forma de diferenciação de produtos, também segundo o relatório da Euromonitor International (2018).

De acordo com dados de tendências e de crescimento do mercado pet food, deste mesmo relatório do Euromonitor International (2018), o mercado latinoamericano de pet food apresentou um desempenho melhor que qualquer outra região do planeta nos últimos anos, crescendo a uma taxa média de $5,7 \%$ ao ano entre 2011 e 2016. As vendas de ração para cães e gatos superam as vendas de rações para qualquer outro tipo de animal de estimação em sete países da América Latina: Brasil, México, Argentina, Chile, Venezuela, Colômbia e Peru. Os latinoamericanos possuem uma atração maior por esses animais de estimação em comparação com outras regiões. Na Europa, as vendas de rações para cães e gatos são praticamente similares às vendas de rações para outros tipos de animais. Na América Latina, contudo, a proporção entre o gasto com ração para cães e gatos e ração para outros animais, em dólares, é de seis para um.

No mercado brasileiro, o segmento da alimentação de cães e gatos se mantém forte, além de o Brasil ser o país com a maior população de cães e gatos da América Latina. O Brasil possui ainda a segunda posição de país com a maior população de cães, gatos e aves (ABINPET, 2018). Espera-se crescimento estável para os próximos anos e, apesar de a taxa anual esperada até 2022 não ser muito impressionante, a tendência é de que a venda de ração animal continue forte na maioria dos países da América Latina, porém a uma taxa menor do que foi visto recentemente. "O crescimento absoluto esperado é, particularmente, interessante para o Brasil, México e Argentina, que deverão apresentar, respectivamente, um aumento de US\$ 857 milhões, US\$ 780 milhões e US\$ 377 milhões entre 2016 e 2021”, conforme Sammy Rolls, analista do Euromonitor International (2018).

O faturamento das vendas no varejo do mercado pet no mundo foi de aproximadamente US\$124,6 bilhões em 2018. Os dez principais mercados do setor pet no mundo representam 75,4\% do total. Destaca-se o mercado dos Estados Unidos, que responde por mais de $40 \%$ das vendas no varejo do setor no mundo. O Brasil passou a figurar como segundo principal mercado, com participação de 5,2\%, enquanto o Reino Unido e a Alemanha o acompanham de perto, com participação próxima de $5 \%$ cada. O Brasil, em 2018, se consolidou como segundo maior mercado pet no mundo, tendo movimentado US\$ 
6,44 bilhões (algo equivalente a $\mathrm{R} \$ 20,7$ bilhões), ultrapassando a Inglaterra, que registrou faturamento de US\$ 6,15 bilhões (Euromonitor International, 2018; Instituto Pet Brasil, 2018).

Os dados recolhidos da Euromonitor International demonstram um sólido crescimento do mercado pet na última década e meia. No Brasil, o crescimento da população de animais de estimação de 2001 a 2015 foi de $42,8 \%$, sendo: $33,8 \%$ de cães, $101,5 \%$ de gatos e $39,7 \%$ de outros pets. Na população canina, os de pequeno porte (até $9 \mathrm{~kg}$ ) representaram o maior crescimento, de 30\% (Freitas, 2016).

Em termos de tipo de alimento, o mercado global é, sem exceção, dominado pela ração seca. A participação de mercado é tão representativa que, mesmo somando-se as participações de mercado de alimento úmido e de snacks, não chegaríamos à parcela de ração seca.

A produção de alimentos para cães e gatos está dividida em empresas nacionais e multinacionais, sendo estas últimas as líderes mundiais neste setor. As 10 maiores empresas, grande parte multinacionais, detêm quase $80 \%$ do mercado pet food. Entre os principais fabricantes, temos as estrangeiras Masterfoods South America (antiga Effen do grupo Mars Inc.), Nestlé Purina, Hill's Pet Nutrition (do grupo Colgate-Palmolive), IAMS Pet Food (Procter \& Gamble), Royal Canin (Mars), e as nacionais Guabi-Mogiana, Nutriara, Alisul, Total, Premier Pet, Socil Evialis, Nutron e Agroceres (Mazon \& Moura, 2017).

A maior empresa do mercado é a Mars, que vendeu cerca de 17,2 bilhões de dólares de pet food em 2018. Os dois principais líderes de mercado são as gigantes Mars e Nestlé (Petfood Industry, 2019). Em 2018, o varejo pet especializado no Brasil registrou um estoque de mais 31 mil estabelecimentos. Dentre esses, a maior parte está na categoria de Pet Shop Loja de Vizinhança (79,6\%), que se caracteriza por apresentar faturamento médio de $\mathrm{R} \$ 60$ mil a 100 mil anuais, possuir até 4 funcionários e oferecer cerca de $30 \%$ da cobertura do mix de produtos pet. As vendas de produtos do setor pet se concentram no comércio especializado $(80,9 \%)$. Já o comércio alimentar, que compreende estabelecimentos como supermercados, responde por 6,3\% das vendas. O comércio eletrônico corresponde a 2,7\% e o comércio direto de animais pelo criador ao tutor, a 10,1\%. O número de pontos de venda de produtos pet no Brasil superou 150 mil estabelecimentos. Dentre esses, cerca de 60\% pertencem à categoria do varejo alimentar. Os pet shops (via canal direto), representados por lojas de médio porte e de vizinhança, também são expressivos, com 20,4\% de participação em mais de 31 mil estabelecimentos, conforme dados do Instituto Pet Brasil (2018).

\section{Planejamento fiscal e tributário}

Para Gallo (2007), a estrutura do sistema tributário brasileiro desenvolveu-se em um ambiente econômico com elevada inflação, o que, inclusive, direcionou as formas de arrecadação das administrações tributárias para os impostos indiretos, incidentes sobre o consumo de bens e serviços, como uma forma de as receitas ficarem menos vulneráveis aos efeitos inflacionários. Todavia, é indispensável analisar a incidência de cada tributo ao longo da cadeia produtiva para identificar a carga tributária efetiva do produto que chega ao consumidor final e assim conhecer a eficiência econômica, segurança jurídica tributária, dispêndios envolvidos e as estratégias mais vantajosas.

A análise da influência da tributação inicia-se na instituição da empresa e no enquadramento fiscal. São importantes as contribuições dos autores Ribeiro \& Mário (2008), sobre a utilização de metodologias de reestruturação societária como ferramenta de planejamento tributário para as empresas. Os autores citados fizeram referência para a importância do planejamento tributário em cenário competitivo, onde este planejamento faz parte da gestão estratégica e tem por finalidade obter a diminuição, postergação ou anulação dos custos tributários das sociedades, assim melhorando a saúde financeira das organizações.

Vale ressaltar que em 2016, a Carga Tributária Bruta (CTB) do Brasil atingiu 32,38\%, contra 32,11\% em 2015, indicando variação positiva de 0,27 pontos percentuais. Essa variação resultou da combinação dos decréscimos em termos reais de 3,5\% do Produto Interno Bruto e de 2,8\% da arrecadação tributária nos três níveis de governo (Receita Federal, 2017). Em 2016, a carga tributária apresentou aumento pelo segundo ano consecutivo, atingindo o patamar de $32,38 \%$ do PIB, ainda aquém dos 33,66\% observados em 2007, antes da crise econômica de 2008. Observa-se que a União foi responsável pela maior parcela de aumento da carga tributária, contribuindo com $66,5 \%$ de crescimento nominal da arrecadação e com 
57\% da variação total em pontos percentuais do PIB. Embora tenha sido responsável pela maior participação no aumento da carga, em 2015, a União reduziu sua participação no total da arrecadação.

Do ponto de vista histórico, observa-se que no período de 2006 a 2015 o Brasil promoveu uma redução na carga tributária, ao passo que a média dos países da OCDE apresentou aumento. Na carga tributária do Brasil, as categorias que apresentaram redução foram renda, bens e serviços e outros (que inclui a extinta CPMF), enquanto que as categorias folha de salário e propriedade apresentaram aumento (Receita Federal, 2017).

Quando se compara a carga tributária do Brasil com a dos demais países da América Latina, observase que o Brasil apresenta uma carga tributária mais elevada. Entretanto, convém sempre atentar aos detalhes metodológicos. Por exemplo, os dados divulgados pela OCDE não incluem os governos locais para alguns países (Receita Federal, 2017).

A incidência de tributos ao longo da cadeia produtiva pode ocasionar distorções consideráveis na eficiência econômica e na competitividade dos mercados doméstico e internacional. Segundo Baleeiro (2013), os tributos indiretos são os que incidem sobre a produção e a circulação de bens e serviços e são repassados para o preço, pelo produtor, vendedor ou prestador de serviço. Os encargos tributários recaem sobre o preço da venda de mercadorias ou serviços prestados, razão pela qual o consumidor final é o contribuinte de fato, pois ao pagar o preço, está pagando também todos os tributos nele contidos.

Quanto ao Imposto sobre Produtos Industrializados (IPI), este tributo não integra a receita bruta, pois como é cobrado à parte do preço de venda, deve também ser contabilizado à parte do respectivo preço; idêntico tratamento deve ser dado ao Imposto Sobre Circulação de Mercadorias e Serviços por Substituição Tributária (ICMS-ST), cobrado destacadamente do preço de venda. Já para o Imposto Sobre Circulação de Mercadorias e Serviços (ICMS) próprio, destacado na nota fiscal, por integrar o preço de venda, como ocorre com o imposto dos Programas de Integração Social (PIS) e a Contribuição para Financiamento da Seguridade Social (COFINS), deve ser computada a receita bruta. Esses valores serão posteriormente deduzidos para se determinar a receita líquida (Viceconti \& Neves, 2013).

Incidem diretamente sobre a renda das empresas dois tributos: o Imposto sobre a Renda e Proventos de Qualquer Natureza (IR) e a Contribuição Social sobre o Lucro Líquido (CSLL). Quando se trata do IR relativo às pessoas jurídicas, é utilizada a sigla IRPJ. A base de cálculo dos dois tributos é o lucro, na forma definida na legislação. Uma vez que cada tributo possui sua legislação específica, o valor em reais da base de cálculo de cada um dos tributos pode ser diferente (Rezende et al., 2010).

Segundo a legislação do IRPJ, o lucro tributável pode ser apurado de quatro maneiras, ou regimes de apuração. Os regimes de tributação da esfera federal existentes no Brasil são: Simples Nacional, Lucro Presumido, Lucro Real e Lucro Arbitrado (Leite \& Oliveira, 2016). O contribuinte pode optar em qual modalidade de apuração quer ser tributado, observadas algumas restrições ligadas à atividade realizada, ao volume de receitas ou eventos justificadores do tratamento excepcional (Rezende et al., 2010).

As pessoas jurídicas que não estão obrigadas à apuração com base no lucro real podem optar por serem tributadas com base no lucro presumido. À semelhança da estimativa mensal, o lucro presumido é calculado aplicando-se um coeficiente sobre a receita bruta e acrescentando-se ao valor obtido os demais rendimentos e ganhos de capital (Viceconti \& Neves, 2013).

Ressalta-se que o mesmo critério adotado para a apuração do IRPJ deverá ser adotado para a apuração da CSLL, ou seja, se o IRPJ for apurado trimestralmente, a CSLL obrigatoriamente também deverá ser apurada trimestralmente. Na hipótese prevista de recolhimento do imposto de renda com base na receita bruta, também a CSLL deverá ser recolhida com base na receita. As pessoas jurídicas que optarem pelo pagamento mensal do IRPJ por estimativa deverão também pagar a CSLL pelo mesmo critério, conforme art. 28 da Lei $\mathrm{n}^{\circ}$ 9.430/96, com nova redação dada pela Lei $\mathrm{n}^{\circ} 12.715$ de 2012, em vigor atualmente (Brasil, 2012).

O PIS e a COFINS são dois tributos previstos pela Constituição Federal, nos artigos 195 e 239. Isso posto, o contribuinte pode ser tributado na modalidade cumulativa, quando optante pelo Lucro Presumido, e pode também ser tributado pelo regime da não cumulatividade, quando optante pelo Lucro Real, conforme as Leis $n^{\circ} 10.637$ de 2002 (Brasil, 2002) e $\mathrm{n}^{\circ} 10.833$ de 2003 (Brasil, 2003a) que instituiram a não cumulatividade desses tributos. 
Segundo Pêgas (2003), o IPI também pode ser considerado um imposto sobre a circulação econômica, sendo cobrado quando os bens são produzidos. O IPI, assim como o Imposto de Renda, está sujeito ao princípio da anterioridade, o que permite a alteração de sua alíquota a qualquer momento, inclusive durante o exercício. Em comparação com o ICMS, ele também é um imposto seletivo, ou seja, cobrado em função da essencialidade do produto.

Conforme Farias (2017), aqueles produtos com maior essencialidade possuem a alíquota menor e, para aqueles outros menos essenciais, como, por exemplo, cigarros e bebidas, as alíquotas são maiores. Assim, o IPI, como um imposto não cumulativo, o qual só se paga pela parcela agregada ao produto, possui como contribuinte de fato o consumidor final, não recaindo nenhum ônus para a empresa industrial.

As operações com produtos industrializados constantes do Capítulo 23 da Tabela do IPI referem-se à produção de alimentos para cães e gatos, e a norma sofreu importante alteração pelo Decreto $\mathrm{n}^{\circ} 8.950$ de 2016 (Brasil, 2016), com efeitos a partir de abril de 2017, ao prescrever de maneira clara a incidência do imposto sobre os chamados alimentos compostos completos, com base na alíquota de $10 \%$, o que não existia no Decreto $\mathrm{n}^{\circ} 7.660$ de 2011 (Brasil, 2011), que até então tratava da matéria.

São contribuintes do ICMS os estabelecimentos industriais, estabelecimentos comerciais atacadistas e varejistas, produtores rurais, empresas produtoras e distribuidoras de combustíveis, empresas mineradoras, empresas prestadoras de serviços de comunicação e empresas geradoras e transmissoras de energia elétrica (Rezende et al., 2010). O ICMS é considerado imposto indireto, não cumulativo e com seletividade em função da essencialidade, ou seja, o legislador pode determinar uma tributação mais onerosa para as mercadorias e serviços de menor essencialidade para a vida humana (Faliguski, $\underline{2010})$.

O ICMS-ST está previsto no artigo 128 do CTN (Código Tributário Nacional), que permite atribuir ao sujeito passivo da obrigação tributária a responsabilidade pelo pagamento do imposto relativo ao fato gerador, facilitando a fiscalização, pois centraliza no contribuinte substituto a obrigação do recolhimento do ICMS devido por toda a cadeia, até o consumidor final. Conforme Faliguski (2010), o contribuinte pode ser substituído (o qual deve efetuar a retenção do imposto) ou substituto (aquele que nas operações ou prestações antecedentes ou concomitantes é beneficiado pelo diferimento do imposto e nas operações e prestações subsequentes sofre a retenção).

O aumento do ICMS-ST em São Paulo, sobre as operações com ração para cães e gatos, veio com a publicação da Portaria CAT 41 de 2017 (DOE, 2017), estabelecendo assim base de cálculo na saída de ração para animais de estimação, a que se refere o artigo 313-J do Regulamento do ICMS a partir de 1 de julho de 2017, que revoga a Portaria CAT 87 de 2015. Com esta medida, o Índice de Valor Adicionado Setorial (IVA-ST), utilizado para calcular a base de cálculo do ICMS-ST devido a título de Substituição Tributária, subiu de 53,81\% para 56,92\%.

A definição de localização de centros de distribuição e o planejamento das atividades logísticas são influenciados por questões tributárias. A depender da localização, poderá se pagar mais ou menos impostos e oferecer solução fiscal, ao mesmo tempo em que se oferece solução logística, podendo fazer a diferença na concretização de um negócio (Moraes \& Souza, 2014).

\section{Premissas do caso hipotético}

A Indústria de ração Alfa, sendo uma indústria de grande porte, possui um faturamento acima do teto do Lucro Presumido de R $\$ 78$ milhões e, obrigatoriamente, foi tributada pelo Lucro Real e não cumulatividade do PIS e da COFINS, pelo ICMS em regime periódico de apuração, obrigada a recolher ICMS-ST e tributada pelo IPI.

Considerou-se, para a simulação, que a indústria vende o pacote de ração por $\mathrm{R} \$ 100,00$. A demonstração de resultado do produto apresentada com base em simulação hipotética de venda de um pacote de ração traz significativas vantagens gerenciais para apoio à tomada de decisão. Com base na demonstração de resultado e utilizando técnicas de análise vertical, é possível identificar a influência de cada tributo no resultado do produto. 
Neste caso foi considerado que o custo do produto representa $60,60 \%$, já reduzidos os aproveitamentos de créditos nas entradas dos insumos para a produção. Assumiu-se os valores de custos e créditos com base em demonstrações contábeis comparativas do setor colhidas na internet, considerando, no custo de produção, $20 \%$ de mão de obra, parcela esta sem direito a créditos e na estrutura de produto e os custos industriais, alguns deles com direito a créditos de impostos.

Foram identificados aspectos relevantes quanto à tomada de créditos e à interpretação da legislação, como oportunidade de redução da carga tributária. Os aproveitamentos dos créditos tributários provenientes dos insumos adquiridos para a produção da ração ainda possuem diversas questões controversas e interpretativas, principalmente aqueles referentes a créditos de PIS, COFINS e ICMS.

Considerou-se a tributação do PIS e da COFINS nas vendas como sendo de 1,65\% para o PIS e 7,60\% para a COFINS, conforme as Leis n 10.637 de 2002 e 10.833 de 2003 (Brasil, 2002, 2003b). O IPI de $10 \%$ foi considerado conforme Decreto ${ }^{\circ} 8.656$, de 29 de janeiro de 2016, porém a carga efetiva do IPI considerada na venda será de $11,11 \%$, uma vez que o cálculo deste tributo é realizado "por fora" do preço do produto e adicionado ao total da Nota Fiscal.

Destarte, os distribuidores, geralmente, enquadram-se no Lucro Presumido e no regime de PIS e COFINS cumulativo, pois são empresas com faturamento menor, algumas ainda são microempresas e empresas de pequeno porte, salvo as grandes redes varejistas. Nestas últimas, os faturamentos ultrapassam o limite da legislação do Lucro Presumido, em cujo caso a tributação dos tributos diretos dependerá da base de lucro auferido. O pet shop estudado foi enquadrado no Simples Nacional e, portanto, recolhe o tributo de forma única e simples.

\section{Apuração da carga tributária da ração}

Quanto à incidência dos tributos diretos, considerou-se um LAIR (Lucro Antes do Imposto de Renda) de $25 \%$ da indústria, tributada pelo Lucro Real, onde a base de incidência do tributo é o lucro, sendo que o IRPJ possui alíquota de 15\%, enquanto o adicional é de 10\% e a CSLL, de 9\% (Brasil, 2018). Considerando o efeito destes tributos em relação ao faturamento, obtém-se uma carga efetiva sobre o faturamento de IRPJ de $3,75 \%$, adicional de $2,50 \%$ e a CSLL de $2,25 \%$.

Somando-se os tributos diretos federais, a alíquota efetiva sobre o faturamento encontrada foi de $8,50 \%$, enquanto os tributos indiretos federais somados totalizam uma alíquota sobre o faturamento de $20,36 \%$. Portanto, incidirão sobre a venda $28,86 \%$ de tributos federais, não considerando o aproveitamento de créditos.

Na venda da ração para cães e gatos, incide o ICMS-ST, em São Paulo, através da Portaria CAT 41 de 2017, que aumenta o IVA-ST para 56,92\%, aplicado para calcular a base de cálculo do ICMS-ST nas operações internas. A base de cálculo para fins de retenção e pagamento do imposto relativo às saídas subsequentes de ração tipo pet, classificada na posição 23.09 da Nomenclatura Comum do Mercosul Sistema Harmonizado - NCM/SH, com destino a estabelecimento localizado em território paulista, será o preço praticado pelo sujeito passivo, incluídos os valores correspondentes a frete, carreto, seguro, impostos e outros encargos transferíveis ao adquirente, acrescido do valor adicionado calculado mediante a multiplicação do preço praticado pelo Índice de Valor Adicionado Setorial - IVA-ST.

O preço do produto considerado foi de 100 reais (para facilitar os cálculos e também por ser um valor bem próximo do praticado atualmente), com um IPI incidindo no valor de R $\$ 11,11$ e o valor do ICMSST encontrado foi de R $\$ 13,38$ (no cálculo do ICMS-ST, como apresentado, o imposto é adicionado à nota fiscal do cliente). No ICMS próprio, a alíquota interna do Estado de São Paulo é de $18 \%$.

Considerando todos os tributos incidentes na indústria, os tributos indiretos (IPI, PIS, COFINS, ICMS, ICMS-ST) e os tributos diretos (IRPJ, adicional e a CSLL), obtém-se uma carga tributária sobre as vendas de 60,24\% (nas saídas), com um LAIR de $25 \%$ para elaboração da simulação. Porém, as indústrias tributadas pelo Lucro Real estão enquadradas na não cumulatividade, onde os créditos dos insumos adquiridos para a produção podem ser aproveitados e abatidos dos valores de débito do imposto que incidem nas vendas.

A carga tributária efetiva da ração vendida pela indústria foi de $52,63 \%$, já descontados os aproveitamentos de créditos. O distribuidor considerado foi tributado pelo Lucro Presumido e, portanto, 
está na cumulatividade de PIS e da COFINS e na presunção do lucro para apuração do IRPJ e da CSLL. Fazendo a relação da carga tributária pelo faturamento, chega-se que a carga tributária efetiva do distribuidor foi de $6,61 \%$ do faturamento.

A carga tributária efetiva do produto representa $41,86 \%$ do preço pago pelo consumidor final, sendo o preço pago pelo consumidor $\mathrm{R} \$ 177,78$ pelo pacote de ração. Desta forma, o consumidor estará pagando, além do produto ração pet, por mais $\mathrm{R} \$ 74,42$ de tributos acumulados e embutidos.

Considera-se que a indústria vendeu por $\mathrm{R} \$ 100,00$ o pacote de ração para o distribuidor e recolheu $\mathrm{R} \$ 52,63$ de tributos. O distribuidor, com margem de $25 \%$, vende para o varejo por $\mathrm{R} \$ 133,33$ e recolhe $\mathrm{R} \$ 8,81$ de impostos, e o pet shop, também com margem de $25 \%$, vende a ração para o consumidor por $\mathrm{R} \$ 177,78$ e recolhe de impostos $\mathrm{R} \$ 12,98$. Portanto, o consumidor, ao pagar $\mathrm{R} \$ 177,78$, estará pagando aproximadamente $\mathrm{R} \$ 74,42$ de impostos, representando $41,86 \%$ do preço pago pela ração.

Quanto ao percentual efetivo de carga tributária ao longo da cadeia produtiva de ração para cães e gatos, verifica-se que a indústria recolhe $52,63 \%$ do seu faturamento, o distribuidor $6,61 \%$ e o pet shop $7,30 \%$, que, somados, totalizam aproximadamente $41,86 \%$ de impostos que o consumidor paga ao comprar a ração para seu animal de estimação, considerando as margens de lucro praticadas em cada fase. Constatamos quanto representa cada etapa da cadeia produtiva de ração para cães e gatos, com relação à arrecadação de tributos, relativos ao preço pago pelo consumidor final.

É notória a dificuldade para se obter a carga tributária efetiva de determinado produto, dada a falta de conhecimento e a dificuldade da aplicação efetiva da norma tributária. Corrobora para isso a falta de fiscalização dos valores de tributos apresentados nos documentos fiscais como valor aproximado dos tributos, quando emitidos para o consumidor. A falta de padronização aumenta a insegurança jurídica, os custos envolvidos na apuração dos tributos e a necessidade de constantes análises e definições de estratégias para se manter a competitividade.

A escolha dos canais de distribuição possui grande influência nos negócios empresariais. Deste modo, a tributação nas vendas pode variar conforme o canal de distribuição escolhido, assim como o crédito tomado pode variar com as definições do setor de suprimentos, conforme a compra de insumos, variando o local, tipo de produto, entre outros.

A verticalização vem apresentando bons resultados para as indústrias que a adotam, apresentando ganhos efetivos da logística e do planejamento tributário. As fazendas produzindo as matérias primas principais para a indústria localizadas na vizinhança representam grande redução de gastos de transportes e ganhos tributários efetivos. As localizações dos centros de distribuição favorecem a disponibilidade imediata dos produtos nos grandes centros consumidores, além de grandes vantagens tributárias.

O regime tributário adotado no segmento industrial é o Lucro Real, obrigatoriamente pelo volume de faturamento, que excede o limite para optar pelo Lucro Presumido e também nesta etapa as margens são menores e o volume maior. Já os centros de distribuição podem optar pela tributação pelo Lucro Presumido com vantagens tributárias, são mais pulverizados e as margens reais são maiores que as margens presumidas da legislação tributária para a ração pet. Esta estratégia tributária adotada representa expressiva vantagem competitiva.

As rações são vendidas para os centros de distribuição, que são empresas distintas, mas podem pertencer ao mesmo grupo econômico, baseado em planejamento logístico e tributário. Com relação ao ICMS, as mercadorias são tributadas apenas nas saídas da indústria, pois é recolhido também o ICMSST.

Portanto, quando a mercadoria é vendida do centro de distribuição para o varejo, as saídas não são tributadas do ICMS, uma vez que a indústria já fez o recolhimento como substituto tributário. Existem diversas vantagens na operação praticada, inclusive tributárias, pois o IVA real é maior do que o IVA praticado pela legislação e as saídas e o recolhido do ICMS-ST pela indústria são com base no IVA proveniente da legislação tributária. 
A indústria, ainda buscando atender a todo tipo de público ao disponibilizar seus produtos prontamente, ainda pode praticar a venda direta para criadores e clínicas veterinárias, além da venda tanto no atacado como no varejo em diferentes canais de distribuição, inclusive televenda e pela internet.

A tributação é influenciada pelo canal de distribuição, afetando diretamente a margem dos produtos vendidos. As principais diferenças tributárias estão principalmente na venda direta ao consumidor (criadores), venda direta para pet shops, venda para distribuidores terceiros e distribuidores do grupo. Deste modo, o produto que passa pelo distribuidor terceirizado acaba chegando ao consumidor final com um preço e carga tributária maiores, gerados pelas transações, fases e despesas de distribuição.

A Receita Federal do Brasil publicou a Solução de Consulta Interna (Cosit) n ${ }^{\circ} 13$, de 18 de outubro de 2018, que traz critérios e requisitos observados para fins de exclusão do ICMS na base de cálculo do PIS e da COFINS, conforme o julgamento do Recurso Extraordinário n ${ }^{\circ}$ 574.706/PR, pelo Supremo Tribunal Federal, em março de 2017, que reconheceu a inconstitucionalidade da inclusão do ICMS na base de cálculo do PIS e da COFINS, tendo em vista que o valor do imposto não constitui receita para a empresa (STF, 2017).

\section{Considerações finais}

Quando se compara a tributação por base de incidência, observa-se que para a base de incidência sobre a renda, o Brasil tributa menos que os países da Organização para a Cooperação e Desenvolvimento Econômico (OCDE), enquanto que para a base de incidência sobre os bens e serviços, categoria onde se encontram inseridas as rações para cães e gatos, a tributação ocorre em níveis mais elevados. Em comparação com os países da América Latina, observa-se que o Brasil apresenta uma carga tributária média mais elevada (Receita Federal, 2017).

A ração apresenta elevada carga tributária quando comparada a outros produtos e à média nacional, principalmente para a indústria. A comparação da tributação da ração para cães e gatos com a tributação da ração para animais destinados à produção e alimentação humana não se fundamenta, por apresentarem cadeias produtivas diferentes e uma sistemática de tributação distinta. A simples comparação da tributação da ração para cães e gatos no Brasil com a tributação da ração para cães e gatos de outros países também não se sustenta, pois os sistemas tributários muitas vezes são distintos, ou seja, organizados de forma diferenciada, podendo ter maior peso na renda do que no consumo de bens e serviços, por exemplo. Percebe-se que o sistema tributário nacional precisa evoluir, uma vez que possui elevada carga nos tributos regressivos, logo penaliza a população menos favorecida com uma tributação maior incidente sobre bens e serviços.

O planejamento tributário é um processo estratégico para as empresas atualmente em ambiente competitivo, notadamente para as do segmento de pet food, que possuem uma elevada carga tributária se comparada com a média nacional de carga tributária em relação ao percentual do PIB brasileiro. Com a análise da carga tributária da ração pet ao longo de sua cadeia produtiva foi possível identificar a tributação do produto em cada fase da cadeia e os valores suportados de impostos pelo consumidor final que adquire esse produto. Conhecer a tributação ao longo da cadeia produtiva traz informações estratégicas sobre a sua influência nos preços e margens desses produtos.

Para a elaboração de um planejamento eficiente, deve-se ter profissionais especializados, profundos conhecedores da legislação tributária e também o envolvimento de todas as áreas da empresa. $\mathrm{O}$ planejamento tributário possui grande impacto nas áreas comerciais, de supply chain e de finanças das firmas. A escolha dos fornecedores na indústria, assim como estratégias de localização de centros de distribuição e do percurso da ração, representam definições estratégicas e influenciam no ônus tributário empresarial.

A utilização do planejamento tributário no segmento pet food possui relevância para que se consiga reduzir os custos tributários e minimizar riscos de contingências, aumentando positivamente as margens de lucro. A área contábil tributária mostrou-se fundamental na gestão empresarial desde a constituição da empresa e durante sua evolução, sendo de cunho estratégico as definições da área tributária, pois podem colocar determinada empresa em condições de vantagem competitiva. A análise dos regimes tributários, opções de tributação e tomadas de créditos influenciam na carga tributária final do produto, podendo reduzir a margem de lucro. 
Demonstrou-se, por meio de caso hipotético, o quanto a carga tributária afeta as margens de lucro empresarial e quanto representam atualmente na análise da demonstração de resultado do exercício das empresas deste segmento. As análises das demonstrações contábeis e financeiras são importantes ferramentas para avaliar a influência da tributação nas margens de lucro.

A carga tributária da ração para cães e gatos encontrada na simulação e calculada com base na legislação vigente quando o produto é adquirido pelo consumidor final foi de $41,86 \%$ de tributos pagos no preço do pacote de ração. Se comparada à carga tributária média nacional, que em 2016 foi de 32,38\% do PIB, nota-se que a tributação da ração pet está $29,28 \%$ maior que a média nacional, ou seja, a ração pet está sendo mais tributada do que diversos outros produtos comercializados no mercado nacional.

Os posicionamentos levantados e as discussões das entidades de representação, como a ABINPET, com relação à carga tributária da ração, são fundamentais para que o governo reconheça a importância deste setor para a economia nacional e os benefícios trazidos pelos animais de estimação à população, de modo geral.

Vale destacar ainda que estratégias de planejamento tributário, quando atuando em conjunto com as demais áreas da empresa, principalmente com a área de supply chain, podem trazer expressivas vantagens monetárias para as empresas e reduzir o ônus tributário do contribuinte.

\section{Referências Bibliográficas}

ABINPET. (2018). Associação Brasileira da Indústria de Produtos para Animais de Estimação. Mercado Pet Brasil.

Baleeiro, A. (2013). Direito Tributário Brasileiro. $13^{\circ}$ Edição, Revista, Atualizada e Ampliada. Rio de Janeiro, RJ: Editora Forense.

Brasil. (2002). Lei $\mathrm{n}^{\mathrm{o}} 10.637$, de 30 de dezembro de 2002 . In Brasil. http://www.planalto.gov.br/ccivil_03/leis/2002/L10637compilado.htm

Brasil. (2003a). Lei ${ }^{\circ}$ 10.753, de 30 de outubro de 2003. https://www2.camara.leg.br/legin/fed/lei/2003/lei-1075330-outubro-2003-497306-publicacaooriginal-1-pl.html

Brasil. (2003b). Lei n ${ }^{\circ}$ 10.833, de 29 de dezembro de 2003. In Altera a Legislação Tributária Federal e dá outras providências.

Brasil. (2011). Decreto $\mathrm{n}^{\circ}$ 7.660, de 23 de dezembro de 2011. https://www2.camara.leg.br/legin/fed/decret/2011/decreto7660-23-dezembro-2011-612196-publicacaooriginal-134813-pe.html

Brasil. (2012). Lei no 12.715, de 17 de setembro de 2012. In CÂMARA DOS DEPUTADOS - Centro de Documentação e Informação. https://www2.camara.leg.br/legin/fed/lei/2012/lei-12715-17setembro-2012-774180-normaatualizada-pl.pdf

Brasil. (2016). Decreto $\mathrm{n}^{\circ}$ 8.950, de 29 de dezembro de 2016. http://www.planalto.gov.br/ccivil 03/ Ato20152018/2016/Decreto/D8950.htm\#art6

Brasil. (2018). Decreto $\mathrm{n}^{\circ} 9.580$ de 22 de novembro de 2018. Regulamenta a tributação, a fiscalização, a arrecadação e a administração do imposto sobre a renda e proventos de qualquer natureza. https://www.in.gov.br/materia/-/asset_publisher/Kujrw0TZC2Mb/content/id/51525535/do1-201811-23-decreto-n-9-580-de-22-de-novembro-de-2018-51525026

DOE. (2017). Diário Oficial do Estado de São Paulo. Portaria CAT 41, de 23 de junho de 2017. https://portal.fazenda.sp.gov.br/DiarioOficial/Paginas/Portaria-CAT-41,-de-23-de-junho-de$\underline{2017 . a s p x}$

Euromonitor International. (2018). Pet Care Industry Overview. In Pet South America 2018. http://petsa.rds.land/pet-care-industry-overview

Faliguski, I. (2010). O impacto da substituição tributária no preço de venda para consumidor final. Trabalho de conclusão de graduação - Universidade Federal do Rio Grande do Sul- Porto Alegre, RS. http://hdl.handle.net/10183/25727

Farias, L. R. B. (2017). A tributação seletiva no IPI e no ICMS: indeterminação e controle do conceito de essencialidade. Dissertação de Mestrado - Universidade Federal de Alagoas.

Freitas, F. J. S. (2016). Ensino de administração nos cursos de medicina veterinária e a visão dos profissionais 
sobre a gestão dos serviços veterinários para pequenos animais diante da expansão do mercado pet [Master's Dissertation- Universidade de São Paulo]. https://doi.org/10.11606/D.74.2017.tde-16032017-095538

Gallo, M. F. (2007). A relevância da abordagem contábil na mensuração da carga tributária das empresas [Doctoral Thesis - Universidade de São Paulo]. https://doi.org/10.11606/T.12.2008.tde$\underline{14052008-112837}$

Heiden, J., \& Santos, W. (2009). Benefícios psicológicos da convivência com animais de estimação para os idosos. ÁGORA: Revista de Divulgação Científica, 16(2esp.), 487-496.

Instituto Pet Brasil. (2018). Mercado Pet No Mundo. In Instituto PET Brasil. https://www.gov.br/agricultura/pt-br/assuntos/camaras-setoriais-tematicas/documentos/camarassetoriais/animais-e-estimacao/2019/26deg-ro-1/14-10ipb_mercado_pet_resultados_2018_draft2.pdf

Leite, C. S., \& Oliveira, V. V. M. (2016). Impostos Aplicados em uma Indústria de Carrocerias: Um Estudo de Caso. Revista de Iniciação Científica Da Libertas, 1(1), 40.

MAPA. (2009). PORTARIA N ${ }^{\circ}$ 3, DE 22 DE JANEIRO DE 2009. Ministério Da Agricultura, Pecuária e Abastecimento - Secretaria de Defesa Agropecuária, 1-15. https://www.gov.br/agricultura/ptbr/assuntos/insumos-agropecuarios/insumos-pecuarios/alimentacao-animal/arquivos-alimentacaoanimal/legislacao/consulta-publica-finalizada-portaria-no-03-de-22-de-janeiro-de-2009.pdf/view

Mazon, M. S., \& Moura, W. G. (2017). Cachorros e humanos: mercado de rações pet em perspectiva sociológica. Civitas - Revista de Ciências Sociais, 17(1), 138. https://doi.org/10.15448/19847289.2017.1.25292

Moraes, M. H., \& Souza, F. A. (2014). Logística Tributária e Fiscal - Aspectos Fiscais e Tributários no Cotidiano das Operações Logísticas. Maringá, SP: Ed. MAG.

Pêgas, P. H. (2003).Manual de Contabilidade Tributária. 471 p. Recife, PE: Freitas Bastos. (2003)

Pessanha, L. D. R., \& Carvalho, R. L. S. (2014). Famílias, animais de estimação e consumo: um estudo do marketing dirigido aos proprietários de animais de estimação. Signos Do Consumo, 6(2), 187. https://doi.org/10.11606/issn.1984-5057.v6i2p187-203

Petfood Industry. (2019). Top Pet Food Companies Current Data. https://www.petfoodindustry.com/directories/211top-pet-food-companies-current-data

Receita Federal. (2017). Carga tributária no Brasil 2016: análise por tributos e bases de incidência. Ministério Da Fazenda, 64. http://idg.receita.fazenda.gov.br/dados/receitadata/estudos-e-tributariose-aduaneiros/estudos-e-estatisticas/carga-tributaria-no-brasil/carga-tributaria-2016.pdf

Rezende, A. J., Pereira, C. A., \& Alencar, R. C. (2010). Contabilidade Tributária: entendendo a lógica dos tributos e seus reflexos sobre os resultados das empresas. In ISBN 978-85-224-5983-4. São Paulo, SP: Atlas.

Ribeiro, A. E. L., \& Mário, P. C. (2008). Utilização de metodologias de reestruturação societária como ferramenta de planejamento tributário: um estudo de caso. Contabilidade Vista \& Revista, 19(4), $107-128$.

TJ-SP. (2018). Poder Judiciário. Tribunal de Justiça do Estado de São Paulo. Agravo de Instrumento $n^{o}$ 2052114-52.2018.8.26.0000 - Voto $n^{\circ} 10559$ L.

Viceconti, P., \& Neves, S. (2013). Contabilidade avançada e análises das demonstrações financeiras. 17. Ed. São Paulo, SP: Saraiva.

Recebido: 19 de julho, 2020.

Aprovado: 14 de agosto, 2020.

Disponível online: 11 de setembro, 2020

Licenciamento: Este artigo é publicado na modalidade Acesso Aberto sob a licença Creative Commons Atribuição 4.0 (CC-BY 4.0), a qual permite uso irrestrito, distribuição, reprodução em qualquer meio, desde que o autor e a fonte sejam devidamente creditados. 